\title{
Mc 8,27-33 \\ UNA PROPUESTA DE IDENTIDAD PARA DISCÍPULOS EN TIEMPOS DE CRISIS
}

\author{
Pablo Vernola \\ Seminario Internacional Teológico Bautista de Buenos Aires \\ pablovernola@sitb.edu.ar \\ (iD) https://orcid.org/0000-0003-1529-8703
}

Resumen: El presente artículo propone una lectura de la perícopa de Mc 8,27-33 desde una metodología contextual, a partir del recurso a su situación histórica originaria. En el marco de la guerra judía, la identidad de los seguidores de Jesús fue puesta en cuestionamiento, especialmente en aquellos que provenían del judaísmo palestinense. La perícopa elegida presenta una "tercera posición" que busca no aliarse al poder romano representado por las referencias a la familia herodiana, ni tampoco a la resistencia armada representada por la confesión "mesiánica" de Pedro y la reprensión dirigida por Jesús. Esta lectura es posible si entendemos el relato como una respuesta al trauma experimentado por sus primeros lectores.

Palabras clave: Marcos. Guerra judía. Identidad. Crisis.

\section{Mk 8:27-33 a proposal of identity for disciples in times of crisis}

Abstract: This paper deals with the pericope of Mk 8:27-33 as an example of reading from a contextual methodology, from the resource of its historical situation. In the framework of the Jewish War, the identity of the followers of Jesus was questioned, especially in those who came from Palestinian Judaism. The indicated pericope presents a "third position" that seeks not to ally itself with the Roman power, represented by the references to the Herodian family, nor to the armed resistance, represented by the "messianic" confession of Peter and the reprimand directed by Jesus. This reading is possible if the story is understood as a response to the trauma experienced by its first readers. 
Keywords: Mark. Jewish war. Identity. Crisis.

... los seres humanos no nacen para siempre el día en que sus madres los alumbran, sino que la vida los obliga otra vez y muchas veces a parirse a sí mismos.

Gabriel García MÁRQUEZ, El amor en los tiempos del cólera

En ocasiones, las situaciones de conflicto y de crisis se presentan como circunstancias en las que la identidad es cuestionada y hasta revisada, tanto a nivel personal como comunitario. Una propuesta de lectura del evangelio de Marcos desde una metodología contextual que lo ubique en su trasfondo histórico originario permite comprender su mensaje como una propuesta de identidad del discípulo, en medio de la enorme crisis que implicó la guerra judeo-romana.

Mediante el análisis de una perícopa concreta del evangelio según Marcos (8,27-33), el presente trabajo intenta dilucidar si tal cuestión relativa al contexto que dio origen al evangelio puede considerarse como un factor de replanteamiento de la identidad en el seno de una comunidad mixta atravesada por una crisis de posguerra y, en tal caso, cuáles serían el mensaje del libro y la alternativa que propone frente a esta crisis.

\section{Consideraciones para una lectura de Marcos en el contexto de la guerra}

Si bien es cierto que la posición tradicional relaciona el evangelio de Marcos con la ciudad de Roma y los años posteriores a la muerte de Nerón, el presente trabajo parte, en cambio, de la idea de que la comunidad a la cual Marcos se dirige está establecida en la zona de Siria. Su proximidad a la zona de Palestina explicaría mejor la fuerte vinculación -tanto temporal como espacial- con la guerra judía del 66-74 d. C. ${ }^{1}$ A fin de fundamentar esta postura, sintetizamos a continuación los argumentos principales.

1 Esta es la posición asumida por autores como Marcus, "Jewish War", 460; GuIjarro, Los cuatro evangelios, 264-269; Theissen, Colorido local, 259-316; Rodríguez Lálz, El Mesías, 259-274; Roskam, Purpose, 75-114. 


\subsection{Fecha y lugar de origen del evangelio de Marcos}

En cuanto a la datación de Marcos, autores como Gerd Theissen y otros más recientes como Joel Marcus, Hendrika Roskam o Ana Rodríguez Láiz sostienen que el evangelio habría sido escrito poco después de la destrucción de Jerusalén, hecho que determinó el final de la guerra. Si bien estos autores recogen otras propuestas de datación del evangelio, como aquellas tradicionales que lo ubican en torno a la persecución de los cristianos en Roma en el año 64 d. C., o las que sostienen que el evangelio se podría haber escrito durante los acontecimientos bélicos ocurridos entre los años 66 y 70 d. C., la conclusión de todos ellos es que son varios los indicios que presenta el texto de Marcos que permitirían leerlo situándolo luego del 70 d. C. En un trabajo relativamente reciente, Christopher Zeichmann analiza Mc 12,13-17, comparándolo con algunos indicadores de la administración geopolítica, la circulación de monedas y las políticas fiscales romanas. Concluye, en el mismo sentido, afirmando que el evangelio no puede haber sido escrito antes de finales del año $71 \mathrm{~d}$. C. ${ }^{2}$

En cuanto al lugar de redacción del evangelio, los autores mencionados también descartan la posición "tradicional" que apunta a Roma como lugar de origen de Marcos. Proponen como alternativa alguna ciudad de Siria, al norte de Palestina, o, en el caso de Roskam, algún lugar en Galilea. Cualquiera que sea la opción que se adopte, se trataría de una zona cercana a los lugares mencionados en el evangelio, varios de los cuales también estuvieron vinculados con la guerra judía. Dicha cercanía convierte al relato en un texto mucho más interpelante para los primeros destinatarios, que se verían afectados directamente por las consecuencias de la guerra, de modo tal que el evangelio podría leerse como la expresión literaria de una reacción frente a la crisis que estaban sufriendo.

\subsection{Posible Sitz im Leben del evangelio de Marcos}

Identificadas la fecha y lugar de origen del evangelio, se puede intentar describir su Sitz im Leben, la situación vital que le habría dado origen. Para ello, sintetizamos a continuación la posición de algunos autores en torno a la interpretación del capítulo 13 de Marcos; analizamos el uso del término euangélion en Mc y su vínculo con el acceso de los Flavios al trono imperial y del término jristós. Por último, buscaremos entender el con-

2 Cf. Zeichmann, “The Date of Mark's Gospel”, 422-437. 
flicto étnico que podría haber dado origen al evangelio de Marcos en el contexto de la guerra judeo-romana.

\subsubsection{La interpretación de Marcos 13}

En primer lugar, diremos que autores como Theissen, Marcus, Roskam y Rodríguez Láiz consideran que una lectura atenta del capítulo 13 de Marcos provee importante información para la determinación del Sitz im Leben del evangelio. En este texto, el evangelista emplearía el lenguaje apocalíptico para reinterpretar la guerra y la destrucción de Jerusalén y su templo. La comunidad no debía alarmarse con "guerras y rumores de guerras", ya que todavía no se trataba del fin, sino solo del comienzo (vv. 7-8): primero debería anunciarse el evangelio a todos los pueblos (v. 10). La guerra judeo-romana no era el fin; había que perseverar en medio de las dificultades y las persecuciones que vendrían (v. 13). Tal como afirma L. Michael White, Marcos utiliza la forma del discurso apocalíptico para reinterpretar la situación vivida por la comunidad, y las esperanzas apocalípticas anteriores que, de alguna manera, habían llevado a muchos sectores de los judíos -tal vez incluso miembros de la comunidad- a levantarse en guerra contra Roma. Se trataría del uso de ideas apocalípticas con el fin de reinterpretar esperanzas apocalípticas anteriores ${ }^{3}$. Teniendo en cuenta la posible ubicación del evangelio en la frontera de Siria con Palestina, donde probablemente surgieron las primeras comunidades cristianas mixtas, Rodríguez Láiz sugiere que estas comunidades no eran bien vistas por los judíos. Es probable que en el contexto de la guerra con Roma sufrieran un cierto acoso de parte de los judíos más radicales, interesados en mantener la pureza de la nación. El evangelista se estaría dirigiendo a una comunidad que está experimentando esta situación e intenta ayudarla mediante su mensaje a "resituar su horizonte" 4 . Según esta autora, Marcos propone una "apocalíptica de la resistencia" 5 .

¿Cuál debería ser la postura de los integrantes de la comunidad de Marcos luego de la guerra? ¿Someterse al imperio romano sin presentar resistencia? ¿Mantener algún tipo de rebelión frente a la opresión pagana, al estilo del partido zelota? En palabras de Guijarro,

3 Cf. White, De Jesús, 293; 301.

${ }^{4}$ Cf. Rodríguez Lálz, El Mesías, 267-268.

5 Ib., 271. 
el hecho de que este evangelio fuera compuesto en medio de una profunda crisis, exigía recuperar la memoria de Jesús de una forma creativa... Este evangelio proporciona un testimonio único sobre un grupo de discípulos de Jesús que tuvo que repensar y expresar su fe en una situación nueva ${ }^{6}$.

En este proceso de profunda crisis, de reelaboración creativa de las tradiciones sobre Jesús, de reflexión y expresión de la fe, la comunidad de Marcos puso en revisión su propia identidad. Esta identidad, como dijimos, se vio afectada por los eventos de la guerra y por su vínculo con las comunidades judías de la zona de Siria, ya que la mixtura en su composición étnica representaría un conflicto frente a los sectores judíos más conservadores.

\subsubsection{Uso del término euangélion y su vínculo con el ascenso de los Flavios}

En segundo lugar, otro elemento a tener en cuenta para comprender la situación vital que dio origen al relato de Marcos es el uso que hace del término euangélion y su relación con el ascenso de la dinastía de los Flavios al trono de Roma. Seguiremos la propuesta de Theissen, en dos de sus obras ${ }^{7}$.

Luego de una importante crisis interna en el imperio romano acompañada de guerras civiles, el ascenso de los Flavios fue considerado por muchos como una buena noticia, como el regreso de la estabilidad y la paz. En los escritos de Flavio Josefo puede encontrarse el término euangélia (plural) empleado en este sentido ${ }^{8}$. A través de diferentes recursos, Josefo intenta proyectar en Vespasiano las expectativas mesiánicas judías, como aquel gobernante que se levantaría del oriente y que llegaría al trono mundial. Vespasiano estaba en Judea (al oriente de Roma) librando una guerra, cuando fue proclamado emperador.

6 Guijarro, Los cuatro evangelios, 279.

7 Cf. Theissen, La redacción, 27-28; Colorido local, 291-298.

8 "Alejandro, ya depositario de los designios de Vespasiano sobre el imperio, preparó lo necesario para su advenimiento. Mucho más rápidamente de lo que podía figurarse se propagó por oriente que Vespasiano era emperador. Todas las poblaciones festejaron la buena nueva y ofrecieron sacrificios en su honor" (JosEfo, Guerra, IV, 618). "Vespasiano se encontraba en Alejandría cuando llegaron las buenas noticias de Roma y alegres embajadas de todo el mundo que, desde aquel momento, le pertenecía" (Ib., IV, 656) [las cursivas son mías]. 
El uso que hace Marcos del término euangélion ${ }^{9}$, que, por otra parte, se trata mayormente de un empleo redaccional del evangelista ${ }^{10}$, podría evidenciar un interés por demostrar cuál es el verdadero "evangelio". La verdadera buena noticia no sería el advenimiento al poder de Vespasiano, sino la llegada del Reino de Dios en la persona de Jesús, Mesías e hijo de Dios, muerto en la cruz y resucitado al tercer día. Según Theissen, a aquellos miembros de la comunidad marcana atraídos por el ascenso del nuevo emperador, el evangelista los corrige con afirmaciones como las que encontramos en Mc 13,21-22.

Así, el evangelio de Marcos es, sin duda, un caso de literatura clandestina de carácter políticamente subversivo. Transmite una imagen del entorno político, a saber, una imagen de contraste, que sirve de guía para la acción. Se supone que la comunidad marcana ha de forjar su forma de vida en contraste con este entorno que amenaza a los cristianos... Brindó a su comunidad orientación en un momento de cambio político; no son los Flavios recién ascendidos quienes traen la salvación al mundo, sino Jesús de Nazaret, el crucificado ${ }^{11}$.

También esto ponía en juego la identidad de la comunidad de Marcos. Los romanos le habían ganado la guerra a los judíos; el general Vespasiano, que iba al frente del ejército, había sido proclamado como el nuevo emperador; y algunos "oráculos" populares indicaban que Dios había guiado todo esto $^{12}$. ¿Cuál debía ser la actitud de los seguidores de Jesús frente a este euangélion del advenimiento de la dinastía flaviana al poder? ¿Debían los miembros de la comunidad alinearse frente al poder imperial, o debían, en cambio, repensar las palabras de Jesús en relación con sus nuevas circunstancias de vida?

\subsubsection{Uso del término jristós y la expectativa mesiánica}

Para determinar el Sitz im Leben del evangelio, también conviene mencionar el uso que hace Marcos del término jristós, vinculado con la expectativa mesiánica de la situación histórica que dio origen al evangelio.

9 Véase Mc 1,1.14.15; 8,35; 10,29; 13,10; 14,9.

10 El carácter redaccional del término euangélion se fundamenta a partir de lo expuesto por Theissen, Colorido local, 263 y MARXSEn, El evangelista, 111-143.

11 Theissen, La redacción, 32, 52.

12 Véase n. 27. 
Según Guijarro ${ }^{13}$, el evangelista se propone explicar a lo largo de todo el relato el significado de los términos "Cristo" e "hijo de David" para intentar corregir en sus lectores posibles comprensiones erróneas, especialmente aquellos sentidos vinculados a connotaciones políticas revolucionarias que pudieran hacer ver a los seguidores de Jesús como enemigos de Roma y resistentes al imperio. Según el autor mencionado, el "secreto mesiánico" que atraviesa todo el evangelio también busca contrarrestar una interpretación del mesianismo de Jesús en clave política. Para ello, Marcos muestra el destino previsto para este Mesías Jesús -la muerte en la cruz- no como consecuencia de que se haya visto a Jesús como un revolucionario, sino como parte del plan divino que motiva su voluntaria entrega.

Este es un rasgo característico del Evangelio de Marcos, que refleja el clima de sospecha y de temor en que vivían sus destinatarios: es necesario ser precavidos con lo que se dice a otros, sobre todo por lo que concierne a ciertas enseñanzas que podrían ser mal interpretadas ${ }^{14}$.

A partir del sentido del término jristós también puede pensarse en un cuestionamiento de la identidad de la comunidad marcana. Siendo los títulos "Cristo" e "hijo de David" tan ambiguos y controvertidos como se expuso, ¿cuál debía ser la posición de la comunidad? ¿Era Jesús el mesías esperado? ¿Qué implicaba que lo fuera? El haber muerto en la cruz como un rebelde al imperio, ¿suponía que ellos debían resistir de igual manera?

\subsubsection{El conflicto étnico en los orígenes de la guerra $y$ del evangelio de Marcos}

Por último, es posible que la crisis que atravesaba la comunidad de Marcos estuviera también relacionada con su identidad étnica. En este sentido, Flavio Josefo describe que, en el origen de la guerra, las primeras revueltas judías estuvieron caracterizadas por conflictos de tipo étnico. Transcribimos a continuación algunas citas del libro II de La guerra de los judíos que atestiguan conflictos de judíos con sirios, griegos o romanos, previos al estallido de la guerra,

En Cesarea estalló otro conflicto, cuando los judíos que vivían allí se sublevaron contra los sirios. La población hebrea decía que la ciudad era de ellos, pues su fundador había sido un judío: el rey Herodes. Por su parte, los sirios

13 Cf. Guijarro, Los cuatro evangelios, 273.

14 lb., 274-275. 
reconocían que el fundador había sido un judío, pero afirmaban que la ciudad era de los griegos, ya que Herodes no habría erigido estatuas y templos en una ciudad para los judíos. Los dos bandos discutían por este asunto. El enfrentamiento los llevó a tomar las armas (II, 266-267).

Al día siguiente, sábado, cuando los judíos estaban reunidos en la sinagoga, un rebelde de Cesarea dio la vuelta a una olla, la colocó a la entrada de la sinagoga y sacrificó en ella unos pájaros. Este hecho produjo una gran indignación entre los judíos, pues se trataba de una ofensa a sus leyes y de una profanación del lugar (II, 289).

El mismo día y a la misma hora, como si de una Providencia se tratara, los habitantes de Cesarea asesinaron a los judíos que vivían en su ciudad, de tal manera que en una hora degollaron a más de veinte mil y toda Cesarea quedó vacía de judíos (II, 457).

Por su parte los sirios no mataron a un número menor de judíos, sino que ellos también degollaron a los que se encontraban en las ciudades, no solo por odio, como ocurría antes, sino ahora también por adelantarse al peligro que se les avecinaba. Unos disturbios terribles se apoderaron de toda Siria: todas las ciudades se dividieron en dos bandos (II, 461-462).

Cabe mencionar que Josefo señala que la revuelta también se extendió a ciudades donde el conflicto se produjo entre distintos bandos de judíos, porque no había acuerdo en cuál debía ser la postura frente a la ocupación romana:

Hasta este momento, los judíos habían tenido enfrentamientos con extranjeros. Sin embargo, al invadir Escitópolis, se granjearon la enemistad de los hebreos que vivían en aquella zona. Estos, tras anteponer su propia seguridad a sus comunes raíces judías, apoyaron a los habitantes de Escitópolis y combatieron contra sus propios compatriotas (II, 466).

Estos testimonios muestran, por tanto, el conflicto étnico entre judíos y paganos, pero también conflictos internos entre diversos sectores judíos. Algunos de estos casos podrían ilustrar tanto la situación tensa y delicada que se vivía durante la guerra, como las consecuencias que tal crisis habría dejado en el período subsiguiente, el período en que se redactó el evangelio según Marcos. Es posible que el conflicto étnico también estuviera presente en la comunidad marcana que -como ya se dijo-presentaba una mixtura en su composición y también sufría las consecuencias de la guerra.

En conclusión, puede detectarse que el evangelio de Marcos habría surgido en un contexto de persecución, ligado a la guerra judeo-romana. La comunidad destinataria, ubicada en la zona de Siria cercana a Palestina, está siendo perseguida de alguna forma, tanto por los romanos que no distinguen 
entre judíos a los miembros del movimiento de Jesús, como por ciertos sectores judíos que ven en la comunidad mixta de Marcos un signo de la impureza de la nación. La convivencia con el mundo gentil, para algunos judíos, es incluso contraria a la dirección tomada por la revuelta zelota contra el Imperio.

En medio de esa situación, la comunidad marcana deberá aclarar su identidad.

\section{La trayectoria de Jesús en el evangelio de Marcos y la guerra judía}

Como hemos notado en el apartado anterior, el trasfondo de la guerra judeo-romana provee un escenario adecuado para leer e interpretar el evangelio de Marcos como un producto literario de ese contexto.

En este segundo apartado, intentaremos vincular las referencias geográficas de la sección de Mc, que comienzan en 8,27, con las encontradas en La guerra de los judíos ${ }^{15}$.

\subsection{La propuesta de Monika Fander}

Fander señala que los principales lugares en los que se desarrolla la guerra judía -Galilea y Jerusalén- coinciden con los centros geográficos del ministerio público de Jesús, tal como se presenta en el evangelio de Marcos. Según la descripción registrada por Flavio Josefo en La guerra de los judios, Galilea y Jerusalén son los únicos lugares en los que hubo luchas significativas o resistencia judía organizada. Fander observa que el camino seguido por Jesús en el relato de Marcos conecta ambos lugares, con el anuncio de la pasión en tres oportunidades ${ }^{16}$. Si seguimos los criterios geográficos para dividir el evangelio, vemos que los principales lugares de la actuación de Jesús son la zona de Galilea, el camino a Jerusalén y la misma ciudad de Jerusalén:

I. 1,1-15. Prólogo

II. $1,16-8,26$. Ministerio en Galilea y su zona

15 Trabajamos a partir de la propuesta realizada por Monika Fander en su artículo: “'Mein Gott, mein Gott, warum hast du mich verlassen?' (Mark 15:34): (Kriegs) Traumatisierung als Thema des Markusevangeliums".

16 Cf. FAnder, “Mein Gott, mein Gott”, 120-122. 
III. 8,27-10,52. Sección "en el camino"

IV. 11,1-15,47. Ministerio en Jerusalén

V. 16,1-8. Epílogo ${ }^{17}$

En el camino que une Galilea y Jerusalén, se mencionan: Cesarea de Filipo (8,27), el cruce por Galilea (9,30), Cafarnaúm (9,33), la región de Judea y al otro lado del Jordán, es decir, Perea $(10,1)$, Jericó $(10,46)$, Betania y Betfagé $(11,1)$, y finalmente Jerusalén $(11,11)$. Fander afirma que esos lugares marcan, según las descripciones de Josefo, la misma ruta que siguió Vespasiano con su ejército al dirigirse a Jerusalén a partir del año 67 d. C.

\subsection{Confrontación de referencias geográficas}

Ofrecemos a continuación un cuadro que intenta reflejar lo mencionado por Fander. Se confrontan las referencias geográficas de Marcos, a partir de Mc 8,27, con la descripción ofrecida por Josefo.

\begin{tabular}{|l|l|}
\hline $\begin{array}{l}\text { Referencias geográficas } \\
\text { en Marcos a partir de 8,27 }\end{array}$ & $\begin{array}{l}\text { Referencias geográficas en La guerra de } \\
\text { los judios de Flavio Josefo }\end{array}$ \\
\hline $\begin{array}{l}\text { 8,27. "Salió Jesús con sus discípulos hacia } \\
\text { los poblados de Cesarea de Filipo..." }\end{array}$ & $\begin{array}{l}\text { III, 443. Cesarea de Filipo. "Vespasiano } \\
\text { levantó campamento y se trasladó... } \\
\text { a Cesarea de Filipo... Permitió que su } \\
\text { ejército descansara allí durante veinte días, } \\
\text { y él mismo participó en banquetes e hizo } \\
\text { sacrificios a Dios..." }\end{array}$ \\
\hline $\begin{array}{l}\text { 9,30. "Salieron de allí y fueron caminando } \\
\text { por Galilea..." } \\
9,33 . \text { "Llegaron a Cafarnaúm..." }\end{array}$ & $\begin{array}{l}\text { III, 447.462. IV, 84. Vespasiano avanza } \\
\text { con su ejército por pueblos de Galilea: } \\
\text { Sennabris, Tiberíades, Tariquea, } \\
\text { Giscala. } \\
\text { IV, 120. "De esta forma fue tomada toda } \\
\text { Galilea, que con muchos sudores sirvió } \\
\text { de entrenamiento a los romanos para la } \\
\text { toma de Jerusalén." }\end{array}$ \\
\hline
\end{tabular}

17 Más allá de cualquier propuesta de estructuración, cabe mencionar lo dicho por Guijarro: “En todo caso, es importante no olvidar que se trata de un relato y que, para leerlo adecuadamente, es necesario tener presente el conjunto. La división en secciones es solo un recurso para facilitar la lectura". GUIJARRo, Los cuatro evangelios, 222. 


\begin{tabular}{|c|c|}
\hline $\begin{array}{l}10,1 \text {. "Dejó aquel lugar y se dirigió a la } \\
\text { región de Judea y al otro lado del } \\
\text { Jordán..." (Perea). }\end{array}$ & $\begin{array}{l}\text { IV, 413. "Vespasiano... se puso en } \\
\text { marcha, en apariencia para asediar } \\
\text { Jerusalén... Era necesario conquistar antes } \\
\text { los enclaves que aún quedaban, para que } \\
\text { no hubiera ningún obstáculo externo } \\
\text { que se opusiera a la toma de la ciudad. } \\
\text { Fue contra Gadara, capital fortificada } \\
\text { de Perea..." } \\
\text { IV, 439. "Así, toda la zona de Perea hasta } \\
\text { Maqueronte se sometió o fue } \\
\text { conquistada." }\end{array}$ \\
\hline 10,46. "Llegaron a Jericó..." & $\begin{array}{l}\text { IV, 450. "Al día siguiente se presentó } \\
\text { en Jericó, donde se reunió con él uno de } \\
\text { sus generales, Trajano, con el ejército de } \\
\text { Perea, cuando ya estaban sometidos los } \\
\text { territorios del otro lado del Jordán." }\end{array}$ \\
\hline $\begin{array}{l}\text { 11,1. "Cuando se aproximaban a } \\
\text { Jerusalén, cerca ya de Betfagé y Betania, } \\
\text { al pie del monte de los Olivos..." } \\
\text { 11,7. "Llevaron al pollino ante Jesús... } \\
\text { y se sentó sobre él..." } \\
\text { 11,11.15.27. Llegadas a Jerusalén y } \\
\text { retiradas. La "Pasión" anunciada se } \\
\text { demora. }\end{array}$ & $\begin{array}{l}\text { IV, } 497.502 \text {. Demoras en la toma de } \\
\text { Jerusalén. "Vespasiano dejó para más } \\
\text { tarde la expedición contra Jerusalén... } \\
\text { pusieron fin a la expedición contra los } \\
\text { judíos." } \\
\text { IV, 550-555. Toma de varios poblados de } \\
\text { Judea: Gofna, Acrabatene, Betel, Efraín. } \\
\text { "Vespasiano... marchó contra las regiones } \\
\text { de Judea que aún no habían sido } \\
\text { sometidas... Marchó a caballo hasta } \\
\text { Jerusalén... La gente de dentro le abrió de } \\
\text { repente las puertas y salió a entregarse a él } \\
\text { como suplicante con ramas de olivo..." }\end{array}$ \\
\hline $\begin{array}{l}\text { 13,1-3. "Al salir del Templo, le dijo uno de } \\
\text { sus discípulos: 'Maestro, mira qué piedras } \\
\text { y qué construcciones'. Jesús le dijo: ‘¿Ves } \\
\text { estas grandiosas construcciones? No } \\
\text { quedará piedra sobre piedra, ni una que no } \\
\text { sea derruida'. Estando luego sentado en el } \\
\text { monte de los Olivos, frente al Templo...” }\end{array}$ & $\begin{array}{l}\text { V, 67. "César... partió hacia el lugar } \\
\text { llamado Escopo, desde donde ya se veía la } \\
\text { ciudad de Jerusalén y la resplandeciente } \\
\text { magnificencia del Templo." } \\
\text { V, 70.135. "A esta legión se le dio la orden } \\
\text { de acampar a seis estadios de Jerusalén, } \\
\text { en el llamado monte de los Olivos... } \\
\text { La décima legión permaneció en su } \\
\text { puesto, en el monte de los Olivos." } \\
\text { Libro VI. La toma de Jerusalén } \\
\text { y destrucción del Templo }{ }^{18} \text {. }\end{array}$ \\
\hline
\end{tabular}

18 También llama la atención cómo puede confrontarse con el relato de Mc la descripción que hace Josefo de los azotes, tortura y muerte por crucifixión de los que huían fuera de la muralla de la ciudad durante el sitio de Jerusalén, previo a su destrucción, y las respectivas burlas de los soldados: "Eran azotados, sometidos a 
El cuadro precedente muestra interesantes similitudes entre el relato de Marcos y los sucesos descriptos por Josefo en su obra. Esto sugiere una posible vinculación entre el texto evangélico y los sucesos de la guerra. Es cierto que la ruta descripta coincide con la que habitualmente se utilizaba para subir a Jerusalén desde Galilea; pero la hipótesis de dicho vínculo se refuerza cuando se analizan también otros aspectos.

Fander afirma que también los detalles particulares de la conquista romana de Palestina se reflejan en las narraciones del evangelio de Marcos. La larga tregua en la toma de Jerusalén a causa de la incertidumbre respecto de la sucesión al trono después de la muerte de Nerón, además de las peleas entre los grupos sediciosos en la ciudad de Jerusalén, hacen posible que Vespasiano instale sin peligro al ejército romano en Jericó y sus alrededores, provocando que la planeada conquista de Jerusalén solo se comience a efectuar en el año 69 d. C. Curiosamente, también hay un "retraso narrativo" en el evangelio de Marcos cuando Jesús llega a Jerusalén. A partir de Mc 8,27, la Pasión ya es un tema dominante en virtud de los tres anuncios realizados; además en Mc 13 ya se predijo la destrucción de Jerusalén; sin embargo, la narración de la Pasión no sigue inmediatamente a la llegada de Jesús a Jerusalén, sino que el texto pasa a describir distintas confrontaciones que tienen lugar en la zona del templo. Fander también destaca el detalle de que Marcos relata entradas y salidas de Jesús en Jerusalén (Mc 11,1.19; 14,3) dilatando la entrada definitiva en la ciudad hasta el comienzo del relato de la Pasión propiamente dicho. Se estaría trazando, entonces, un paralelismo con la instalación del ejército romano en Jericó durante un año, antes que la guerra terminara con la destrucción de la ciudad y el templo en el año 70.

\subsection{La propuesta de Stephen Kimondo}

En una obra reciente -producto de su tesis doctoral- Stephen Kimondo también se esfuerza por mostrar los puntos en común entre el relato de Marcos y los hechos relativos a la guerra. Para este autor, los vínculos más

todo tipo de torturas antes de morir y crucificados frente a la muralla... Los soldados romanos, por ira y por odio, para burlarse de ellos colgaban de diferentes formas a los que atrapaban y eran tantas sus víctimas que no tenían espacio suficiente para poner sus cruces ni cruces para clavar sus cuerpos" (Josefo, Guerra, V, 449-451). Dichas imágenes de torturas, que quedarían en la memoria de testigos y a lo largo de varias generaciones, vendrían a la mente de los destinatarios de Mc al leer pasajes relativos a la muerte de Jesús por crucifixión fuera de la ciudad, las torturas a las que fue sometido y las burlas de los soldados (cf. Mc 15,16-24). 
significativos se dan a partir de la mención de Cesarea de Filipo en Mc 8,27, la visita de Jesús a dicha ciudad, su mesianismo y el viaje a Jerusalén; datos que la audiencia de Marcos no podría haber evitado asociar con los acontecimientos bélicos relacionados con Vespasiano y Tito ${ }^{19}$. Es sugerente que Marcos decida llevar a Jesús a una ciudad tan alejada del resto de los acontecimientos narrados y que justo allí, y antes de comenzar su camino hacia Jerusalén, sea declarado por primera vez "Mesías" (8,27-30). Cesarea de Filipo fue la ciudad del descanso de Vespasiano luego de la victoria en Galilea, y el lugar del comienzo de su marcha hacia la Ciudad Santa. Es posible que los primeros oyentes de Marcos vincularan esa ciudad con los acontecimientos recientes de la guerra y con quien era el actual emperador.

También es interesante subrayar una nueva -y última- mención que hace Josefo de Cesarea de Filipo, luego de la destrucción de Jerusalén y su templo. Según Josefo, allí Tito,

... permaneció durante mucho tiempo y ofreció todo tipo de espectáculos. En esta ciudad perecieron muchos prisioneros de guerra, unos fueron arrojados a las fieras y a los demás se les obligó a luchar en grupos unos contra otros, como si fueran enemigos ${ }^{20}$.

Es notable que las dos escenas que Josefo sitúa en Cesarea de Filipo coinciden con los momentos en que los generales al frente del ejército romano descansan con sus tropas al finalizar la conquista de un lugar importante en la guerra ${ }^{21}$ :

- El general Vespasiano descansa con sus tropas luego de la toma de Jotapata, lugar central de la resistencia judía en Galilea, según Josefo (III, 443).

- El general Tito descansa y celebra largamente con sus tropas luego de la destrucción de Jerusalén (VII, 23-24).

A través de lo expuesto en el presente apartado, podemos apreciar los valiosos vínculos entre la descripción del trayecto de Jesús en Marcos y los sucesos de la guerra tal como los describe Josefo. Con esto no pretendemos afirmar que Marcos conociera la obra de Josefo, sino que podría depender de algún tipo de memoria colectiva de los sucesos recientes de la guerra. La cercanía temporal y geográfica entre la comunidad marcana y

19 Cf. KImondo, The Gospel, 5-6.

20 Josefo, Guerra, VII, 23.24.

21 Cf. Kutsko, “Caesarea Philippi”, ABD. 
los acontecimientos bélicos expuestos en el apartado anterior refuerzan dicha hipótesis.

\section{Mc 8,27-33 como "tercera posición"}

Como ya dijimos, la identidad de los seguidores de Jesús integrantes de la comunidad marcana fue puesta en cuestión por las circunstancias. En el momento en que se escribió el evangelio de Marcos todavía no podía distinguirse claramente entre "cristianos" y "judíos"; mucho menos en el contexto siro-palestinense que le dio origen. Siendo la comunidad de Marcos un grupo mixto desde el punto de vista étnico, cabe preguntarse cómo reaccionaron sus miembros judíos frente al estallido de la guerra. Muchos se vieron confrontados por la situación y los miembros judíos de esta comunidad no tendrían por qué haber sido la excepción.

Hendrika Roskam considera que la comunidad cristiana de Marcos era independiente de la sinagoga judía y tenía sus propias reglas, reuniones, ritos de iniciación y comidas comunitarias. La autora sostiene que, a los ojos de los principales judíos, dicha comunidad debe de haber parecido un grupo socialmente desviado, que rompía con el judaísmo ${ }^{22}$.

\subsection{Cesarea de Filipo como el escenario}

Como dijimos en el apartado anterior, la escena de Mc 8,27-33 está ubicada estratégicamente en Cesarea de Filipo. La única referencia a esta ciudad en todo el evangelio de Marcos está en esta perícopa (y en el resto del Nuevo Testamento solo aparece en Mateo 16,13, texto paralelo al que estamos estudiando). La ciudad estaba ubicada a $40 \mathrm{~km}$ al norte del lago de Galilea, al pie del monte Hermón y en el límite con la provincia de Siria, que es la zona de la comunidad de Marcos. También recordamos que Flavio Josefo mencionaba a la ciudad de Cesarea de Filipo en dos ocasiones de relevancia en La guerra de los judíos. Por tratarse de una ciudad tan cercana al límite de Galilea con Siria, y tan significativa desde el punto de vista histórico por la relación con la guerra, la perícopa aquí analizada se transforma en un texto especialmente interpelante para sus primeros lectores ${ }^{23}$.

22 Cf. Roskam, Purpose, 139.

23 Cabe aclarar que Josefo menciona a la ciudad de Cesarea de Filipo en cuatro ocasiones en Guerra: las dos referidas (III, 443; VII, 23); en II, 168, mencionándola como ciudad fundada por Filipo; y en III, 510, en la que solamente se realiza una 
Kimondo recordaba que Cesarea de Filipo fue la ciudad en la que Vespasiano descansó luego de su exitosa campaña bélica en Galilea, poco tiempo después de haber recibido la "profecía" de Josefo de que sería el próximo emperador, y justo antes de comenzar su campaña hacia Jerusalén en el verano del año 67 d. C. En esta misma ciudad de Cesarea de Filipo, es donde Marcos ubica a Jesús luego de su exitosa campaña de vida en Galilea, caracterizada por los milagros, las liberaciones y las alimentaciones multitudinarias; y es allí donde Jesús es declarado Mesías, poco antes de comenzar su camino hacia Jerusalén ${ }^{24}$. Las similitudes parecen intensificarse.

En Mc 7,24.31 son mencionadas las ciudades de Tiro y Sidón, que también podrían sonar familiares y cercanas a la comunidad destinataria.

Podemos sugerir que en Mc 8,27-33 la intención del autor es llevar a Jesús lo más lejos posible en su recorrido geográfico y lo más cerca posible de la comunidad destinataria, para introducir el diálogo que seguirá a continuación. Según el texto de Marcos, es en territorio prácticamente pagano donde Jesús interpela por primera vez a sus discípulos acerca de su identidad. En un territorio similar, los seguidores de Jesús de la comunidad de Marcos están siendo sometidos a las mismas preguntas. La cuestión relativa a la identidad de Jesús afectaría directamente la cuestión de la identidad de los discípulos de la comunidad marcana.

\subsection{La interpretación del mesianismo}

Jesús interpela a sus discípulos con dos preguntas. La primera apunta a conocer lo que dicen los hombres acerca de él. Las respuestas de los discí-

descripción geográfica del lago de Gennesar, el Jordán y sus fuentes. Por otro lado, en II, 459 se hace mención a "Cesarea" como una de varias ciudades arrasadas por los judíos durante las primeras revueltas previas al estallido de la guerra, luego de que los habitantes de Cesarea Marítima asesinasen a mucha población judía de la ciudad. El texto dice: “Después fueron contra Gadara, Hipo y la Gaulanítide, y, tras sembrar la destrucción y la quema por unos lugares y por otros, llegaron a Cadasa, ciudad de los tirios, Ptolemaida, Gaba y Cesarea". Sería lógico comprender esta mención de "Cesarea" como Cesarea de Filipo, tal como señala Jesús Nieto Ibáñez en la nota al pie de su traducción de la obra de Josefo, ya que estaba situada en Galilea como los otros enclaves allí citados y por considerarse muy difícil que los judíos pudieran llevar a cabo semejante destrucción en Cesarea Marítima, sede del procurador romano. De tratarse de Cesarea de Filipo, la mención de II, 459 sumaría de manera notable en la argumentación para el presente trabajo, ya que la ciudad habría estado emparentada directamente con el estallido de la guerra. Como no hay claridad al respecto, se prefiere dejar relegada la mención en la presente nota.

24 Cf. Kimondo, The Gospel, 15-16. 
pulos están enmarcadas en la tradición profética: Juan el Bautista, Elías o uno de los profetas $($ Mc 8,28) y se asemejan a otras dadas por Herodes y su entorno (Mc 6,14-16). La segunda pregunta, "Pero vosotros, ¿quién decís que soy yo?" es respondida por Pedro, quien declara: "Tú eres el Cristo" $(8,29)$.

Como es sabido, el término jristós es ambiguo y representaba una gran diversidad de expectativas en los distintos sectores del judaísmo. Es evidente, por la reacción de Jesús reprendiéndoles para que a nadie dijeran nada acerca de él $(8,30)$, que para el evangelista dicha respuesta necesitaba aclaraciones. Por esta razón, la segunda parte de la perícopa $(8,31-33)$ incorpora el primer anuncio de la pasión que provee la "clave hermenéutica" para comprender el mesianismo de Jesús.

En el contexto de la guerra judeo-romana en el que Marcos escribe, varios líderes judíos se habían levantado como "salvadores", liderando distintos focos de resistencia, en muchos casos armada ${ }^{25}$. Joel Marcus señala que la revuelta judía contra los romanos parece haber sido liderada por figuras mesiánicas de línea davídica ${ }^{26}$. En este sentido es muy sugerente la afirmación de Josefo:

Pero lo que más les impulsó a hacer la guerra fue un oráculo ambiguo, contenido también en sus libros sagrados, según el cual en aquella época un personaje de su país regiría al mundo. Ellos creían que se trataba de alguien de su raza y muchos sabios se equivocaron en su interpretación, ya que el oráculo se refería al principado de Vespasiano, que había sido proclamado emperador en Judea ${ }^{27}$.

25 De los mencionados por Josefo, pueden destacarse a Manaem y Simón ben Giora: “... Manaem, hijo de Judas el galileo... condujo a sus familiares a Masada, donde violentó la armería del rey Herodes, y armó a su gente y a otros ladrones. Rodeado por esa especie de guardia personal, regresó como un rey a Jerusalén, y asumiendo la jefatura de la sedición dirigió el asedio del palacio... llevando vestiduras reales y marchando seguido por sus guardias armados" (Josefo, Guerra, II, 433-434). “Simón pensó entonces engañar a los romanos, asustándolos. Vistiendo una túnica blanca y un manto de púrpura, emergió en el lugar donde antes estaba el Templo. Los que lo vieron quedaron al principio atónitos, y no se movieron..." (/b., VII, 29-30).

26 Cf. Marcus, “Jewish War”, 457.

27 Josefo, Guerra, VI, 312-313. Dichas predicciones mencionadas por Josefo son mencionadas también por otros historiadores romanos, como Suetonio y Tácito: “Se había extendido por todo el Oriente la vieja y firme creencia de que, según estaba escrito, por este tiempo el imperio caería en manos de unas personas venidas de Judea. Aplicándose a ellos mismos esta predicción, que iba referida a un general romano, como luego los hechos lo demostraron, los judíos se rebelaron..." (SuETonio, Vidas de los doce Césares, VIII, 5). “... la mayor parte (de los judíos) estaban confiados en lo que decían los antiguos libros sacerdotales: 'que en aquel mismo tiempo había de prevalecer Oriente, y que saldrían de la Judea los que habían de 
En referencia a la mencionada cita, Marcus afirma que, si bien la base bíblica de este oráculo no está clara, al menos muestra el papel vital que jugó la expectativa mesiánica en alimentar la rebelión ${ }^{28}$. Esto explicaría, de alguna forma, la ambigüedad con la que Marcos aborda el título "hijo de David" a lo largo de su evangelio, impregnado de expectativas mesiánicas erróneas desde su punto de vista.

¿Es Jesús el Cristo, como afirmó Pedro $(8,29)$ ? Todo parecería indicar que sí, teniendo en cuenta que el autor mismo lo anticipó a sus lectores en la primera frase del evangelio: "Principio del evangelio de Jesús, el Cristo, hijo de Dios" $(1,1)^{29}$. Pero la reacción tan vehemente de Jesús (usando el verbo epitimáo, "reprender, ordenar enérgicamente") muestra que para el evangelista la declaración de Jesús como el Cristo o Mesías debía aclararse o complementarse.

Jesús cumplía las expectativas mesiánicas de un modo totalmente imprevisto, entregando su vida en la cruz como hijo de Dios. Dicha entrega de la propia vida no entraba en las categorías mesiánicas judías contemporáneas a la comunidad de Marcos. La propuesta de Jesús presentada por el evangelista surgía como absolutamente novedosa: es el Mesías e hijo de Dios en cuanto es rechazado por los hombres, muerto y resucitado al tercer día $(8,31)$.

Por su parte, para Kimondo estos relatos respaldan un vínculo entre la declaración de Jesús como el Mesías y las reivindicaciones mesiánicas de Vespasiano como el cumplimiento del ambiguo oráculo judío. Lo más probable es que los lectores de Marcos evaluaran la proclamación de Jesús como el Mesías, en Cesarea de Filipo, en relación con Vespasiano, quien se había convertido en emperador gracias a las afirmaciones mesiánicas y divinas que se hicieron sobre él pocos años antes ${ }^{30}$.

\subsection{Mesianismos nacionalistas o mesianismos imperialistas}

Frente a la enseñanza clara de Jesús $(8,31)$, la reacción de Pedro no se hace esperar y es él quien reprende ahora a Jesús llevándolo aparte $(8,32)$.

dominar al mundo'. Estas palabras ambiguas se referían a Vespasiano y Tito; pero el vulgo -como suele acaecer por las pasiones humanas- interpretó para sí tanta grandeza de los hados, y ni siquiera con las adversidades se rendían a la evidencia" (TÁcıto, Historias, V, 13).

28 Cf. MARcus, “Jewish War”, 457.

29 No se aborda en el presente trabajo el problema de crítica textual que presenta Mc 1,1 y que puede verse en RodríGuez Lálz, El Mesías, 44-46.

30 Cf. Kimondo, The Gospel, 8, 152, 183-184. 
Pedro presenta dificultades para comprender la propuesta mesiánica de Jesús que incluye la entrega de su vida. Dicha confusión podría representar a aquellos integrantes de la comunidad marcana con dificultades para comprender el mesianismo de Jesús que no incluye la rebelión anti-romana. Aquí es necesario recordar que los integrantes de la comunidad estaban siendo perseguidos por dos frentes: un frente romano que no distinguía entre judíos y seguidores de Jesús llamado "Mesías" (título con implicancias de rebelión con carácter sedicioso); y un frente judío tradicional que entendía que la convivencia en la comunidad marcana entre judíos y gentiles representaba esa misma apertura a los paganos, que había llevado a Israel a ser víctima de la opresión romana ${ }^{31}$.

La propuesta mesiánica de Jesús en Marcos es absolutamente novedosa, pero también motivo de incomprensión, resistencia y persecución. En el texto, la reacción de Jesús tampoco se hace esperar: Jesús interpela a Pedro a volver detrás suyo, en su condición de discípulo, y lo reprende afirmando que hay solo dos alternativas: pensar como Dios o pensar como los hombres $(8,33)$. La opción de Pedro representaría la segunda y por eso se convierte en "Satanás", al intentar resistir al plan de Dios. Jesús es un Mesías dispuesto a entregar la propia vida y que invitará a sus discípulos a adoptar la misma actitud (8,34-35). Como afirma Rodríguez Láiz,

Jesús rechaza la crítica de Pedro acusándole de tener una mentalidad humana. Es decir, la idea de Pedro acerca de cómo Jesús es el mesías se basa en expectativas humanas, no en el plan de Dios. El Mesías de Dios llevará a cabo el plan divino, no el humano, y este plan divino incluye sufrimiento, muerte y resurrección... El evangelista señala que Jesús no actuará como un mesías dinástico, tal como Pedro espera que lo haga. Se rechaza la idea de que el mesías sea un futuro rey que lleve a cabo las esperanzas nacionalistas de los judíos ${ }^{32}$.

Es en este sentido que la muerte de Jesús en la cruz no es un fracaso como Mesías, ni un destino fatal al no haber podido alcanzar la victoria bélica, sino la entrega voluntaria de la vida y el designio de un plan divino.

Las respuestas populares sobre la identidad de Jesús $(8,28)$ recuerdan los temores de la corte herodiana y la decisión de asesinar a Juan el Bautis-

31 Dicho doble frente de persecución puede notarse en Mc 13,9: “En cuanto a vosotros, mirad por vosotros mismos, pues os entregarán a los tribunales, seréis azotados en las sinagogas y compareceréis ante gobernadores y reyes por mi causa, para que deis testimonio ante ellos". La referencia a "sinagogas" y "gobernadores y reyes" confirmaría el doble frente judío y romano de persecución que estaba sufriendo la comunidad de Marcos.

32 Rodríguez Lálz, El Mesías, 70-71. 
ta (6,14-29). De alguna manera, la idea de persecución y muerte por parte del imperio puede verse reflejada en dicha perícopa, en la referencia indirecta a la corte de Herodes Antipas, gobernante y representante de una dinastía aliada al imperio. El mismo poder que había perseguido y asesinado al Bautista, y que había sido partícipe en la muerte de Jesús a manos de Pilato $(15,15)$, estaba representando ahora una amenaza para la comunidad de $\operatorname{Marcos}^{33}$. Esta referencia anti-romana también puede leerse en la declaración de Pedro sobre Jesús como el Mesías (jristós, v. 30) y, sobre todo, en la reprimenda de Jesús al advertirles no hacer mención de esto.

Según Roskam, la profesión de Jesús como el Cristo o ungido podía ser tomada como una indicación de su subversión debido a las connotaciones que tenía dicho título en el judaísmo de la época, usado en las Escrituras para designar a las personas de la realeza. El futuro rey denominado "Cristo" podría reinar sobre un Israel libre e independiente, ya que el título tenía claras connotaciones políticas, que podían responder a ideas y aspiraciones nacionalistas judías ${ }^{34}$.

Con una interpretación distinta del uso del concepto "mesías", Theissen sugiere que Marcos no lo estaría usando en referencia a los patriotas judíos autoproclamados "mesías" que se rebelaron contra los romanos, sino a Vespasiano mismo, que había usurpado las expectativas mesiánicas de los judíos y se proponía a sí mismo como el salvador del imperio ${ }^{35}$. Según Theissen, a este Vespasiano pseudo-mesías haría referencia Mc 13,22: "Pues surgirán falsos cristos y falsos profetas, que realizarán señales y prodigios con el propósito de engañar, si fuera posible, a los elegidos".

${ }^{33}$ Según Kimondo, los oyentes del evangelio de Marcos pueden haber asociado la historia de Herodes Antipas con Herodes Agripa II por varias razones. Primero, ambos gobernantes llevan el nombre de Herodes. Puesto que Marcos usa solo "nombre familar", Herodes, los oyentes pueden ser libres de asociar el personaje con alguien que les sea familiar y que lleve el mismo nombre. En segundo lugar, las acciones de los dos gobernantes revelan una serie de paralelos. Por ejemplo, ambos gobernantes sirvieron como títeres de los romanos; ambos reyes fueron anfitriones de figuras de alta posición social con banquetes fastuosos: Herodes Agripa II recibió a Vespasiano y a sus tropas en Cesarea de Filipo, así como Antipas celebró su banquete de cumpleaños con sus cortesanos y líderes de Galilea. Para los oyentes de Marcos, el nombre Herodes puede haber evocado recuerdos de Herodes Agripa, quien había sido gobernante de Judea durante todo el período de la guerra (cf. Kimondo, The Gospel, 210).

${ }^{34}$ Cf. Roskam, Purpose, 140.

35 Cf. Theissen, Colorido local, 294. 


\subsection{Un mesianismo de "tercera posición"}

La persecución sufrida por la comunidad marcana de parte de sectores provenientes del judaísmo puede verse en la mención del sufrimiento y del rechazo de Jesús por parte de ancianos, sumos sacerdotes y escribas (v. 31). En la perícopa siguiente (8,34-38), el llamado de Jesús a negarse a uno mismo, tomar la cruz, seguirlo y estar dispuesto a dar la propia vida por él y por el evangelio, muestra que el anuncio de la Pasión estaba interpelando a toda la comunidad marcana. Los padecimientos también sobrevendrían a la comunidad, y, en ese momento, ¿cuál sería la posición que deberían asumir?

Mc 8,27-33 presenta una "tercera posición" que no busca la alianza con el poder romano de Vespasiano, representada por las referencias a la familia herodiana; pero tampoco la resistencia armada representada por la confesión "mesiánica" de Pedro. Dicha tercera posición está anunciada en la reprensión dirigida por Jesús ${ }^{36}$ a Pedro. La confusión que manifiesta Pedro, representa la confusión de identidad que está viviendo la comunidad: ¿cómo ser discípulo de Jesús en tiempos de crisis y guerra?, ¿cómo resignificar la identidad del discípulo en esta nueva situación?

Es la frase final de Jesús (v. 33) la que propone esta tercera posición: la comunidad deberá buscar los pensamientos de Dios y no los de los hombres. Ni una resistencia armada frente a los romanos (sectores revolucionarios judíos), ni una alianza con el poder romano sin ningún tipo de resistencia, que pondría en crisis su identidad. En línea con la propuesta de Rodríguez Láiz, parece que el intento de Marcos de desvincularse del título "hijo de David" tenía que ver con una búsqueda de modelos mesiánicos no nacionalistas, que dieran sentido a la experiencia de sufrimiento y persecución en la que vivían sus comunidades ${ }^{37}$. En definitiva, tanto el sometimiento al imperio como la revolución armada eran expresiones de una misma posición: los "pensamientos de los hombres".

El Jesús de Marcos desafía a los discípulos y a la comunidad a identificarse con los "pensamientos de Dios", siguiendo el modelo de Jesús, de una resistencia no violenta frente a la persecución. La comunidad de Marcos deberá adoptar este modelo. Como sugiere Theissen, "la pasión es el modelo de conducta para su comunidad [...], la historia de la pasión se lee como una 'parénesis para situación de conflicto': a la luz de un conflicto con el

36 Debe notarse la repetición de la acción "reprender" (epitimáó) en los vv. 30, 32 y 33.

37 Cf. Rodríguez Lálz, El Mesías, 247. 
entorno que puede afectar a todos los discípulos" ${ }^{38}$. El modelo del mesías Jesús, su sufrimiento y su pasión, dan la clave para que la comunidad interprete sus propios sufrimientos, les encuentre un sentido y reconfigure su propia identidad de discípulos. Es en el sufrimiento del Mesías que la comunidad puede encontrar sentido a su propio sufrimiento. La comunidad tiene que plantarse frente a la persecución judía y a la opresión romana desde este nuevo lugar lleno de significado. Esta lectura que estamos proponiendo es posible si entendemos el relato como respuesta al trauma experimentado por sus primeros lectores.

\section{Conclusión}

El exégeta neozelandés Warren Carter ${ }^{39}$ sugiere que, frente a las imposiciones de un poder dominante, como el de un imperio, la resistencia puede expresarse de diversas maneras. Una de ellas es la sublevación violenta, modelo claramente ejemplificado por la guerra de judíos contra romanos, que es el trasfondo del evangelio según Marcos. Carter afirma que, en caso de que no hubiera una sublevación violenta, eso no significaría que no haya protesta; la protesta puede ser expresada de otros modos. Uno de ellos es "contar historias que ofrezcan una alternativa o contra-ideología para negar la ideología dominante de la élite y para afirmar la dignidad o igualdad de quienes no pertenecen a ella" ${ }^{40}$.

Probablemente, la perícopa de Mc 8,27-33 juegue ese rol en el relato del evangelio. Frente a la crisis de la guerra y la persecución, la comunidad de Marcos se ve confrontada a repensar su identidad con el fin de reaccionar al contexto y de encontrar sentido en medio de su sufrimiento. La expectativa mesiánica judía que había llevado a muchos a levantarse en armas contra los romanos no debía confundir a los miembros de la comunidad que podían estar experimentando una seria crisis de identidad frente al fin de la guerra: ¿seguían siendo judíos los que formaban parte de la comunidad?, ¿el seguimiento de Jesús los habilitaba para quedar al margen de la revuelta?, ¿debían someterse al imperio, sin ejercer ningún tipo de resistencia?

Los líderes judíos que perseguían a la comunidad de Marcos la veían como algo diferente a la sinagoga. La mixtura de su composición la con-

38 Theissen, Colorido local, 308.

39 Cf. Carter, El imperio, 25-27; 175-207.

$40 \mathrm{lb} ., 26$. 
vertía en una comunidad altamente reprobable, sobre todo en términos étnicos y religiosos. Su convivencia con los gentiles seguidores de Jesús era signo de la infidelidad al Dios de Israel.

La comunidad de Marcos necesitaba reconfigurar su identidad en medio de la crisis. Los "pensamientos de los hombres" debían ser descartados, tanto en la opción del judaísmo resistente al imperio romano que entendía el mesianismo en términos de "hijo de David", rey libertador de Israel del yugo opresor pagano; así como en la opción de sujeción y sumisión al "mesianismo" de Vespasiano que se propone como el salvador del mundo. La tercera posición -"los pensamientos de Dios"- es una forma de resistencia no violenta: el Cristo es Jesús de Nazaret, crucificado no por rebeldía al imperio romano, sino por aceptar el destino divino y entregar su propia vida. Un estilo novedoso de mesianismo que generó resistencias incluso dentro de la comunidad, como la que queda reflejada en la actitud de Pedro (Mc 8,32). Pero solo esta tercera posición de resistencia no violenta les permitiría reconfigurar su identidad frente al enorme trauma experimentado, y dar un nuevo sentido al sufrimiento vivido.

"Los seres humanos no nacen para siempre el día en que sus madres los alumbran, sino que la vida los obliga otra vez y muchas veces a parirse a sí mismos", decía García Márquez en su obra El amor en los tiempos del cólera. En este caso, las circunstancias de la vida estaban obligando a los cristianos de la comunidad de Marcos a "parirse a sí mismos" nuevamente, hallando en Jesús la clave de ese nuevo nacimiento que les permitiría reconfigurar su identidad como sus seguidores.

\section{Bibliografia}

CARTER, W., El imperio romano y el Nuevo Testamento, Estella 2011.

FANDER, M., “'Mein Gott, mein Gott, warum hast du mich verlassen?' (Mark

15:34): (Kriegs) Traumatisierung als Thema des Markusevangeliums", en E. Moltmann-Wendel - R. KirchHoff (eds.), Christologie im Lebensbezug, Göttingen 2005.

Flavio Josefo, La Guerra de los Judíos, Traducción y notas de J. Nieto IвÁÑEZ, Madrid 2017.

KImOndo, S., The Gospel of Mark and the Roman-Jewish War of 66-70 CE. Jesus'Story as a Contrast to the Events of the War, Oregon 2018.

Kutsko, J., "Caesarea Philippi", en D. Freedman (ed.), The Anchor Bible Dictionary, New York 1992.

GuiJarro, S., Los cuatro evangelios, Salamanca 2012. 
Marcus, J., El evangelio según Marcos. Nueva traducción con introducción y comentario, Salamanca 2010-2011.

Marcus, J., "The Jewish War and the Sitz im Leben of Mark", JBL 111 (1992) 441-462.

MarXsen, W., El evangelista Marcos. Estudio sobre la historia de la redacción del evangelio, Salamanca 1981.

Rodríguez Láız, A., El Mesías hijo de David. El mesianismo dinástico en los comienzos del cristianismo, Estella 2016.

Roskam, H., The Purpose of the Gospel of Mark in Its Historical and Social Context (NTSuPPL I I 4), Leiden 2004.

Suetonio, Vida de los doce Césares, Madrid 2017.

TÁcito, Obras completas, Madrid 1946.

Theissen, G., Colorido local y contexto histórico en los evangelios. Una contribución a la historia de la tradición sinóptica, Salamanca 1997.

Theissen, G., La redacción de los evangelios y la política eclesial. Un enfoque socio-retórico, Estella 2002.

White, L., De Jesús al cristianismo. El Nuevo Testamento y la fe cristiana: un proceso de cuatro generaciones, Estella 2007.

Zeichmann, C., "The Date of Mark's Gospel apart from the Temple and Rumors of War: The Taxation Episode (12:13-17) as Evidence", $C B Q 79$ (2017) 422-437.

[recibido: 11/08/19 - aceptado: 9/12/19] 